\title{
Transesterification of activated sludge in subcritical solvent mixture
}

\author{
Phuong Lan Tran-Nguyen ${ }^{\mathrm{a}}$, Alchris Woo Go ${ }^{\mathrm{b}}$, Suryadi Ismadji ${ }^{\mathrm{c}}$, Yi-Hsu Ju ${ }^{\mathrm{a}, *}$ \\ ${ }^{a}$ Department of Chemical Engineering, National Taiwan University of Science and Technology, 43, Keelung Road, Section 4, Taipei 10607, Taiwan \\ ${ }^{\mathrm{b}}$ Department of Chemical Engineering, University of San Carlos - Talamban Campus, Nasipit, Talamban, Cebu City 6000, Philippines \\ ${ }^{\mathrm{c}}$ Department of Chemical Engineering, Widya Mandala Surabaya Catholic University, Kalijudan 37, Surabaya 60114, Indonesia
}

\section{H I G H L I G H T S}

- Produce biodiesel from activated sludge in subcritical methanol with acetic acid.

- Require much shorter time and much less methanol than acid catalyzed method.

- Less severe operation condition than that of supercritical methanol method.

\section{A R T I C L E I N F O}

\section{Article history:}

Received 22 May 2015

Received in revised form 2 August 2015

Accepted 3 August 2015

Available online 20 August 2015

\section{Keywords:}

Acetic acid

Activated sludge

Biodiesel

In situ transesterification

Subcritical solvents
G R A P H I C A L A B S T R A C T

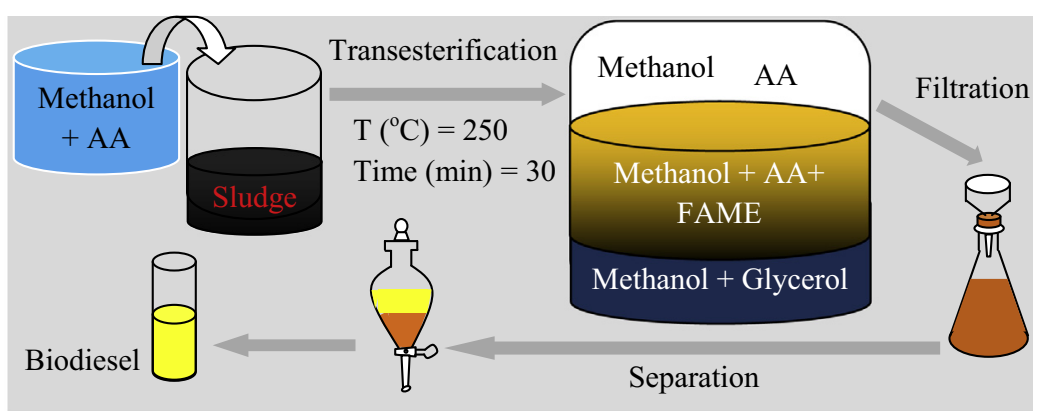

\section{A B S T R A C T}

Most previous studies reported in literature on biodiesel production from sludge were performed by acid catalyzed transesterification that required long reaction time (about $24 \mathrm{~h}$ ) and high methanol loading. The objective of this study was to investigate the in situ transesterification of sludge in subcritical mixture of methanol and acetic acid. At $2500^{\circ} \mathrm{C}$ and a solvent (85\% methanol and $15 \%$ acetic acid) to sludge ratio of $5\left(\mathrm{~mL} \mathrm{~g}^{-1}\right)$, a FAME yield of $30.11 \%$ can be achieved in $30 \mathrm{~min}$, compared to the yield of $35 \%$ obtained by the acid-catalyzed $\left(4 \% \mathrm{H}_{2} \mathrm{SO}_{4}\right)$ transesterification which required $24 \mathrm{~h}$ at $55^{\circ} \mathrm{C}$ and a methanol to sludge ratio of $25\left(\mathrm{~mL} \mathrm{~g}^{-1}\right)$. The method developed in this study avoided using mineral acid, significantly reduced reaction time and methanol loading to achieve comparable FAME yield.

(C) 2015 Elsevier Ltd. All rights reserved.

\section{Introduction}

Due to global warming caused by excessive emission of greenhouse gases, particularly carbon dioxide and the increasing energy demand, there is an urgent need to find alternative fuels to replace the traditional fossil-based fuels. Biodiesel is one of the candidates to solve the environmental pollution, reduce dependence on

Abbreviations: AA, acetic acid; FAME, fatty acid methyl ester; FFA, free fatty acid; HTGC, high temperature gas chromatography; SCW, subcritical water.

* Corresponding author. Tel.: +886 2 27376612; fax: +886 227376644.

E-mail address: yhju@mail.ntust.edu.tw (Y.-H. Ju). limited resources and increase the use of renewable resources. Biodiesel seems a very interesting alternative fuel for reasons such as it is renewable, less global warming than petroleum fuel, biodegradable and less toxic (Ahmad et al., 2012).

Biodiesel is mainly produced from transesterification reaction of vegetable oils or animal fats with alcohol, usually methanol in the presence of an acidic/basic catalyst, with glycerol as a co-product (Fan and Burton, 2009). Vegetable oil is the selected candidate of first generation biofuels in the past centuries (Mythili et al., 2014). Edible oils like soybean oil, sunflower oil, palm oil, rapeseed oil and peanut oil are considered as the biodiesel raw materials. Atabani et al. (2012) claimed that more than $95 \%$ of 
the world biodiesel is produced from rapeseed oil (84\%), sunflower oil and palm oil (13\% and $1 \%$, respectively), and soybean oil and others (2\%). However, those vegetable oils are also used for human consumptions. It can result in an increase of food price, causing high biodiesel cost, fuel crisis, and environmental problems (Atabani et al., 2012; Mata et al., 2010). Moreover, depending on feedstock, biodiesel was sold at a price 1.5-3.0 times higher than that of petroleum diesel (Fan and Burton, 2009). In order not to compete with edible vegetable oils and reduce biodiesel price, low cost feedstock such as non-edible oils, used cooking oils, animal fats, soap-stocks, and greases should be considered as feedstock to produce biodiesel (Mata et al., 2010).

Some recent studies have reported the potential of municipal sludge as biodiesel feedstock. Mondala et al. (2009) obtained a maximum FAME yield of $2.5 \%$ from secondary sludge and estimated that using in situ transesterification the price of biodiesel from sludge ( $\$ 3.23 /$ gallon) could be lower than that of petroleum diesel ( $\$ 4.80 /$ gallon) and soybean biodiesel $(\$ 4.50 /$ gallon). Dufreche et al. (2007) estimated that the price of biodiesel could be $\$ 2.50 /$ gallon at an overall sludge biodiesel yield of $10 \%$, which is competitive with soybean biodiesel in the market. Revellame et al. (2011) reported a sludge biodiesel yield of 3.93\% under the following conditions: reaction temperature $75^{\circ} \mathrm{C}$, ratio of methanol to sludge $30 \mathrm{~mL} \mathrm{~g}^{-1}$, sulfuric acid concentration $10 \mathrm{wt} . \%$, reaction time $24 \mathrm{~h}$. In another study, they obtained a biodiesel yield of $4.79 \%$ in $24 \mathrm{~h}$ at $55{ }^{\circ} \mathrm{C}$, a methanol to sludge ratio of $25 \mathrm{~mL} \mathrm{~g}^{-1}$ using 4 vol.\% sulfuric acid as the catalyst (Revellame et al., 2010). Production of biodiesel from wet activated sludge under subcritical condition at $175^{\circ} \mathrm{C}$ was performed by Huynh et al. (2012). They reported a biodiesel yield of $45.58 \%$ in $8 \mathrm{~h}$.

To date, reports on biodiesel production from activated sludge are limited in literature. Most studies on biodiesel production from activated sludge employed conventional acid catalyzed transesterification which required long reaction time ( $24 \mathrm{~h}$ ) and high ratio of methanol to dried sludge. There is no report on biodiesel production from activated sludge with the aim to reduce reaction time using subcritical mixture of methanol and AA. In this study, subcritical methanol was used to shorten the reaction time. The effect of methanol loading was also investigated to minimize the amount of methanol required. The effect of adding AA on reducing reaction time and increasing FAME yield was studied.

\section{Methods}

\subsection{Materials}

Chemicals including methanol (99.9\% purity), AA (99\% purity), hexane (95\% purity) were obtained from commercial sources and were of analytical reagent grade. Standards of FFAs, acylglycerides and FAMEs were purchased from Supelco (Bellfonte, PA).

The activated sludge sample used in this study was collected from Hsin-Tung-Yang LTD Da-Yuan Factory which is a food processing plant. Water content of the wet sludge sample was 89.01\% (Tran-Nguyen et al., 2013). The wet sludge was dried under sunlight. It was then ground and sieved. Powders that pass through standard mesh $24(0.71 \mathrm{~mm})$ but retained in mesh $60(0.25 \mathrm{~mm})$ were collected. The sludge powder was heated to $105^{\circ} \mathrm{C}$ for $8 \mathrm{~h}$ to remove its residue moisture before use. The dried sludge was then stored at $-20^{\circ} \mathrm{C}$ before use. The moisture content of the dried sludge is $4.88 \%$. Before biodiesel production, activated sludge was dried in an oven overnight and its moisture content was determined.

Water content $\left(M_{\mathrm{S}}\right)$ of a sludge sample was determined from the difference between weight of the sludge sample before and after drying at $105^{\circ} \mathrm{C}$, as shown in the following equation:
$M_{\mathrm{S}}=\frac{\left(W_{\mathrm{WS}}-W_{\mathrm{DS}}\right)}{W_{\mathrm{WS}}} \times 100$

where $M_{\mathrm{S}}$ is water content (\%), $W_{\mathrm{Ws}}$ and $W_{\mathrm{DS}}$ are the sludge weight before and after drying, respectively.

\subsection{In situ transesterification reaction}

In situ transesterification reaction was performed based on the procedure of Huynh et al. (2012). Dried sludge and methanol either with AA or without AA, were loaded into a glass chamber $(190 \mathrm{~mL})$ and then placed in a high pressure reactor $(290 \mathrm{~mL})$. Experimental set up for in situ transesterification of activated sludge is depicted in Fig. 1. The reactor is equipped with an external electric heater. Stirring was provided by an external magnetic stirrer. Temperature in the reactor was controlled to within $\pm 2{ }^{\circ} \mathrm{C}$.

After sample was put in the reaction chamber, the reactor was sealed and carefully insulated. The reactor was heated to the desired temperature in about $60 \mathrm{~min}$ at a heating rate of about $4{ }^{\circ} \mathrm{C}$ per min. The time the reactor temperature reached the desired temperature was set as time zero. After the reaction, the reactor was cooled to ambient temperature, the product was collected and solid was separated by filtration. The solid was washed twice each with $50 \mathrm{~mL}$ methanol. The washed solution was pooled with the liquid phase from filtration. Solvent in the combined solution (methanol and AA) was removed by a vacuum evaporation (BUCHI Labortechnik AG in Flawil, Switzerland) operated at $40{ }^{\circ} \mathrm{C}$ and $13.3 \mathrm{kPa}$ to obtain the crude product. Hexane $(100 \mathrm{~mL})$ and salt solution (5\% sodium chloride) $(20 \mathrm{~mL})$ were added into the separatory funnel to separate crude FAME from the aqueous phase and remove glycerol and residue acetic acid. The upper phase containing FAME was withdrawn and hexane was then removed by using a rotary evaporator. Crude FAME was weighed and its composition was analyzed by HTGC. At least two experiments were carried out for each reaction. The flowchart of the in situ reaction is presented in Fig. 2.

FAME yield is defined as the mass of FAME produced per mass of dried activated sludge used in the reaction and is calculated using Eq. (2)

Yield $(\%)=\frac{\text { Mass of FAME in the product }(\mathrm{g})}{\text { Mass of dry activated sludge }(\mathrm{g})} \times 100$

\subsection{Determination of FAME yield by HTGC}

Before analyzing, $20 \mathrm{mg}$ sludge FAME sample was dissolved in $1 \mathrm{~mL}$ ethyl acetate and filtered using magnesium sulfate to remove moisture. A $1 \mu \mathrm{L}$ aliquot of ethyl acetate solution was injected in a Shimadzu GC-2010. External standard calibration curves were prepared by using $0.2-20 \mathrm{mg}$ pure standards dissolved in ethyl acetate. A 37 components FAME mix standard was used to identify individual FAME in the product.

Chromatographic analysis was performed using a GC-2010 gas chromatograph (Shimadzu, Japan) equipped with a flame ionization detector. Separation was run on a ZB-5HT (5\% phenyl) methylpolysiloxane nonpolar column $(15 \mathrm{~m} \times 0.32 \mathrm{~mm}$ i.d., $0.1 \mu \mathrm{m}$ film thickness, Zebron, Phenomenex, Torrence, CA, USA). The carrier gas was nitrogen with a linear velocity of $30 \mathrm{~cm} \mathrm{~s}^{-1}$ at $80^{\circ} \mathrm{C}$. The operating conditions were as follows. Both injector and detector temperatures were set at $370^{\circ} \mathrm{C}$. The initial oven temperature began at $80^{\circ} \mathrm{C}$, increased to $365^{\circ} \mathrm{C}$ at $15^{\circ} \mathrm{C} \mathrm{min}-1$ and held for $8 \mathrm{~min}$. The total analysis time was $29 \mathrm{~min}$. The hydrogen flow, air flow and make up flow were set at $50.0 \mathrm{~mL} \mathrm{~min}^{-1}$, $500.0 \mathrm{~mL} \mathrm{~min}^{-1}$ and $30 \mathrm{~mL} \mathrm{~min}^{-1}$, respectively while the linear velocity and purge flow were $8.0 \mathrm{~cm} \mathrm{~s}^{-1}$ and $3.0 \mathrm{~mL} \mathrm{~min}^{-1}$, respectively. Data analyses were carried out by the software "GC Solution version 2.3", Shimadzu. 


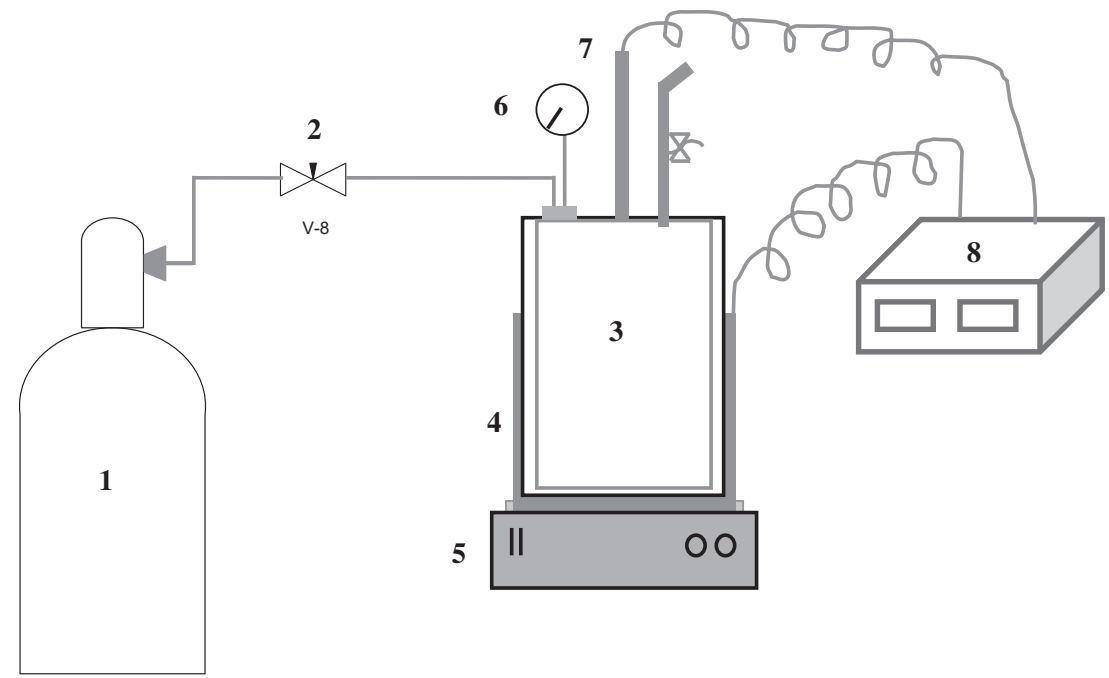

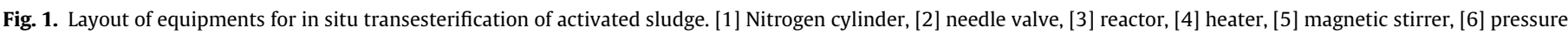
gauge, [7] thermo couple, [8] controller.

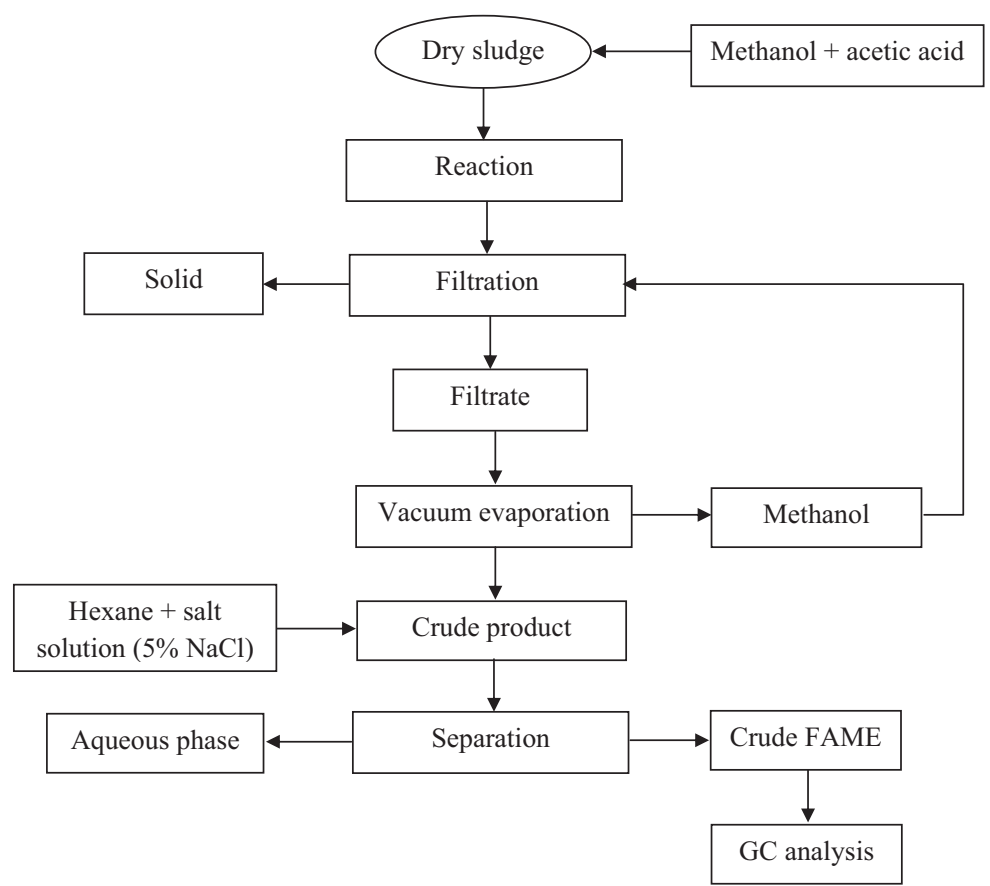

Fig. 2. Flowchart of biodiesel production from dried sludge.

\section{Results and discussion}

\subsection{Characteristics of activated sludge}

Table 1 shows the crude lipid content of AS before and after SCW treatment. Before treatment, the extractable lipid content was $17.99 \%$, which was increased 2.54 times to $45.42 \%$ after SCW treatment. In addition to increase of crude lipid, neutral lipid content also increased 2.33 times after SCW treatment. This increase of extractable lipid after SCW treatment was the result of SCW hydrolysis of phospholipids which are microbial by-products resulting from microbial activity such as death and lysis in wastewater treatment (Olkiewicz et al., 2015). SCW pretreatment can release lipids from other macromolecules which may not be extractable. FFA content and fatty acids profiles of the activated sludge oil were reported by Tran-Nguyen et al. (2013).
Table 1

Characteristics of lipid in dry activated sludge before and after SCW treatment (TranNguyen et al., 2013).

\begin{tabular}{lcc}
\hline & \multicolumn{2}{c}{ Lipid mass fraction dry activated sludge (\%) } \\
\cline { 2 - 3 } Composition & Before SCW pretreatment & After SCW pretreatment ${ }^{\mathrm{a}}$ \\
\hline Unsaponifiable & 0.50 & 5.75 \\
Wax and gums & 1.21 & 1.71 \\
Neutral lipid & 16.28 & 37.96 \\
\hline
\end{tabular}

a Pretreatment condition: $175^{\circ} \mathrm{C}, 4 \mathrm{MPa}, 15 \mathrm{~min}$.

\subsection{FAME production from activated sludge}

Reaction temperature is the major parameter influencing transesterification process. Therefore, in the preliminary investigation of this study, the effect of temperature on FAME yield was investi- 
gated from $200{ }^{\circ} \mathrm{C}$ to $250{ }^{\circ} \mathrm{C}$ for $30 \mathrm{~min}$ with $30 \mathrm{~mL}$ methanol per gram dried sludge (data not shown). It was found that FAME yield was $7.32 \%$ at $200{ }^{\circ} \mathrm{C}$ and increased rapidly to $23.47 \%$ at $250{ }^{\circ} \mathrm{C}$, an increase of about 3.2 times. It may be due to the increase of miscibility between methanol and oil thus an increase of reaction rate (Amit, 2012). Miscibility of methanol and oil are poor at room temperature. Reaction rate increased with increasing temperature owing to increase in solubility of methanol in the oil-rich phase. Higher reaction temperature results in shorter reaction time in mass transfer controlled reaction because esterification reaction is more preferred at higher temperature (Noureddini and Zhu, 1997). In addition, increasing temperature results in decreasing polarity of methanol and this leads to enhancing the solubility of fatty acids in methanol. Kusdiana and Saka (2004) also reported that in supercritical state, methanol acts as an acid catalyst in (trans)esterification reaction. A reaction temperature of $250{ }^{\circ} \mathrm{C}$ was chosen for all experiments in this study, which is a little higher than the critical temperature of methanol $\left(239.6{ }^{\circ} \mathrm{C}\right)$; however, the reaction was still happened under subcritical condition because of the presence of lipids which have much higher critical temperatures.

\subsubsection{Effect of reaction time on FAME yield}

Most of the studies on biodiesel production from sludge by acid catalyzed transesterification were carried out at 50 to $75^{\circ} \mathrm{C}$ for $24 \mathrm{~h}$ (Dufreche et al., 2007; Mondala et al., 2009; Revellame et al., 2010, 2011). Choi et al. (2014) produced biodiesel from wet sludge with hexane as the co-solvent at $55^{\circ} \mathrm{C}$ with a methanol to sludge ratio of $10 \mathrm{~mL} \mathrm{~g}^{-1}$ and reported a FAME yield of $9.68 \%$ in $8 \mathrm{~h}$. Acid-catalyzed in situ transesterification of greasy sewage sludge with methanol using hexane as the co-solvent was reported by Gerhard et al. (2015). A maximum methyl esters yield of $61 \%$ was achieved in $7 \mathrm{~h}$ at $55^{\circ} \mathrm{C}$ and a methanol to sludge ratio of $20 \mathrm{~mL} \mathrm{~g}^{-1}$.

The effect of reaction time on FAME yield was investigated by carrying out reactions at $250{ }^{\circ} \mathrm{C}$ with a methanol to dry sludge ratio of $30 \mathrm{~mL} \mathrm{~g}^{-1}$ for up to $240 \mathrm{~min}$. It was found that FAME yield increased with reaction time and reached a maximum of $28.98 \%$ at $120 \mathrm{~min}$ (Fig. 3), then decreased slightly to $25.70 \%$ as the reaction time was prolonged to $240 \mathrm{~min}$. It was possibly the results of reverse transesterification and formation of fatty acids (Encinar et al., 2012; Eevera et al., 2009).

Compared to conventional acid/base catalyzed reaction, in situtransesterification eliminates the oil extraction step, thus process

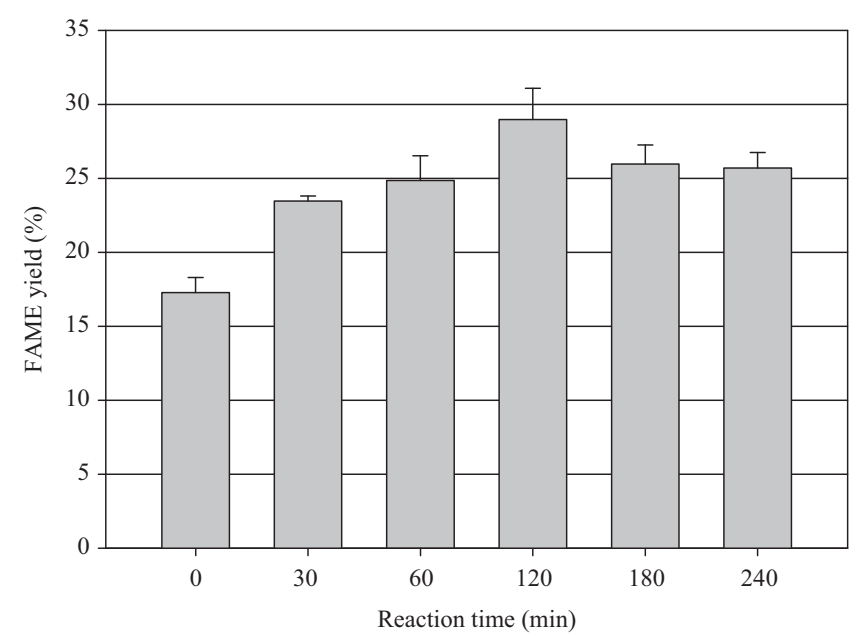

Fig. 3. Effect of reaction time on FAME yield at $250^{\circ} \mathrm{C}$ with a methanol to dry sludge ratio of $30 \mathrm{~mL} \mathrm{~g}^{-1}$. productivity can be improved. In fact, a FAME yield of $28.98 \%$ was achieved in 120 min which is comparable to that of the study of Huynh et al. (2012) and conventional acid catalyzed transesterification (Mondala et al., 2009; Revellame et al., 2010) but required $8 \mathrm{~h}$ and $24 \mathrm{~h}$, respectively. However, by extending reaction time to $180 \mathrm{~min}$ and $240 \mathrm{~min}$, FAME yield decreased slightly to $25.97 \%$ and $25.70 \%$, respectively. This may be because the reaction has reached equilibrium.

\subsubsection{Effect of methanol to sludge ratio on FAME yield}

One of the most important parameters affecting the transesterification reaction is the mass ratio of methanol to biomass used in the reaction. Theoretically, transesterification requires three moles of methanol per mole of triglycerides. The optimum molar ratio of methanol and Cynara oil to obtain high FAME yield by alkali catalyzed transesterification was between 4.05 and 5.67. Uncompleted reaction and difficult separation between methanol and glycerol occurred when molar ratio of methanol to triglycerides were less than 4.05 and higher than 5.67, respectively (Kusdiana and Saka, 2001; Encinar et al., 1999).

In this study, the effect of methanol to dry sludge ratio on FAME yield was investigated by varying the ratio from $1: 1$ to $40: 1 \mathrm{~mL} \mathrm{~g}^{-1}$ at $250{ }^{\circ} \mathrm{C}$ for $120 \mathrm{~min}$ and the results are depicted in Fig. 4 . It can be observed that FAME yield increased from $20.17 \%$ to $28.98 \%$ as methanol to dry sludge ratio was increased from $1: 1$ to $30: 1 \mathrm{~mL} \mathrm{~g}^{-1}$. Even at a methanol to dried sludge ratio of $1 \mathrm{~mL} \mathrm{~g}^{-1}$, FAME yield could reach about $20 \%$. Biodiesel yield increased as more methanol was used. The best result was obtained at a methanol to dried sludge ratio of $30 \mathrm{~mL} \mathrm{~g}^{-1}$. Since the transesterification is a reversible reaction, excess methanol is required to shift this equilibrium towards the formation of FAME (Encinar et al., 2012). Additionally, in the study of the kinetics of transesterification of rapeseed oil in supercritical methanol, it was reported that higher molar ratio of methanol to oil resulted in better FAME yield owing to the increase of contact area between oil and methanol (Kusdiana and Saka, 2001).

However, further increase in methanol loading tended to have negative effects on FAME yield which decreased slightly to $25.56 \%$ as the ratio of methanol to dry sludge was increased to $40 \mathrm{~mL} \mathrm{~g}^{-1}$. This is possibly the result of dilution effect as more amount of methanol was used. Another reason to avoid using too much methanol is that high methanol loading interferes with the separation between glycerol and FAME because of increase of glycerol in FAME as well as difficulty in washing step and

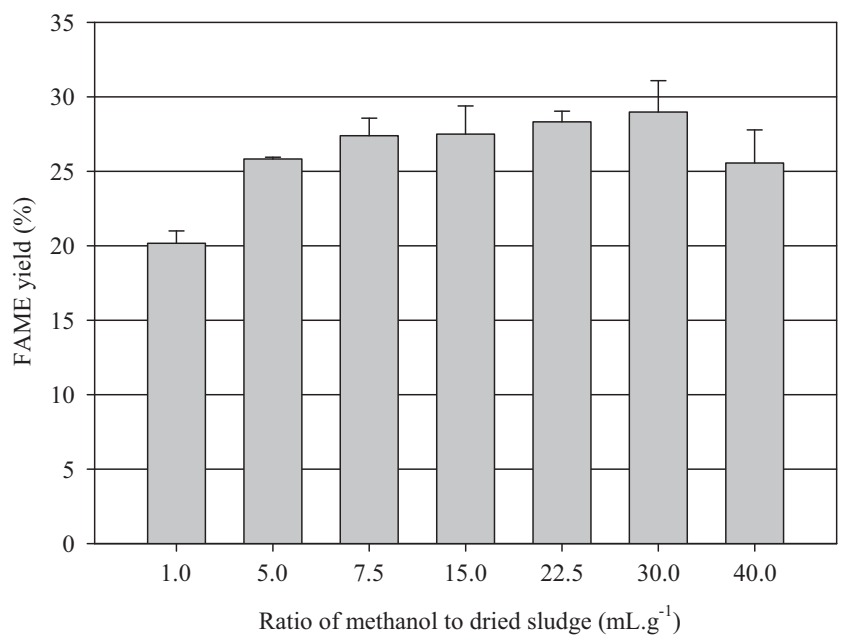

Fig. 4. Effect of methanol to dry sludge ratio on FAME yield. Reaction temperature $=250^{\circ} \mathrm{C}$, reaction time $=120 \mathrm{~min}$. 
contamination of biodiesel product (Encinar et al., 2012). This trend is in agreement with the study of Huynh et al. (2012) which reported that a ratio of methanol to dry activated sludge higher than $30 \mathrm{~mL} \mathrm{~g}^{-1}$ resulted in lower FAME yield. It may be because excess methanol favors extraction of more polar compounds, such as carbohydrate, proteins and pigments as well as the formation of mono-glyceride as explained in the Section 3.2.1. Excess methanol produces more glycerol which increases the driving force of reverse reaction. In addition, excess methanol increases the cost of methanol recovery.

Following the study of Revellame et al. (2011), acid catalyzed transesterification of dry sludge was carried out at $55^{\circ} \mathrm{C}$ by using a methanol to dried sludge ratio of $25 \mathrm{~mL} \mathrm{~g}^{-1}$ and $4 \% \mathrm{H}_{2} \mathrm{SO}_{4}$ (v/ v). FAME yield was $11.38 \%$ at $2 \mathrm{~h}$ and reached a maximum value of $35.28 \%$ at $24 \mathrm{~h}$. This maximum FAME yield is higher than the maximum FAME yield achievable $(\sim 29 \%)$ in the subcritical methanol transesterification at $250^{\circ} \mathrm{C}$; however much shorter reaction time $(2 \mathrm{~h})$ was required in the latter case. Acid catalyst $\left(\mathrm{H}_{2} \mathrm{SO}_{4}\right)$ is required in the former method which requires washing to remove acid from product. On the contrary, the latter process does not require the use of mineral acid.

A methanol to dry sludge ratio of $5 \mathrm{~mL} \mathrm{~g}^{-1}$ was selected for the following study since increasing this ratio from 5 to 30 (an increase of $500 \%$ ), FAME only increased from $25.83 \%$ to $28.98 \%$ (an increase of $12 \%$ ). Furthermore, lowering the amount of methanol used is favorable to reduce the cost of biodiesel production.

\subsection{Effect of $A A$ on FAME yield}

Biodiesel productions from sludge using mineral acid, mostly $\mathrm{H}_{2} \mathrm{SO}_{4}$, as catalyst have been investigated by Dufreche et al. (2007), Mondala et al. (2009) and Revellame et al. (2010, 2011). However, there is no report on biodiesel production from activated sludge under subcritical methanol condition with addition of AA, an organic acid. At a solvent (methanol $+A A$ ) to dry sludge ratio of $5 \mathrm{~mL} \mathrm{~g}^{-1}$, the effects of the amount of AA added on FAME yield are presented in Fig. 5.

The use of $15 \% \mathrm{AA}$ in the solvent mixture (methanol to $\mathrm{AA}=4.25: 0.75)$ enables the reaction to reach a FAME yield of $30.11 \%$ in 30 min, which is about $86 \%$ of that of the acid catalyzed transesterification $(\sim 35 \%)$ that required a reaction of $24 \mathrm{~h}$. Saka et al. (2010) proposed the kinetics of the transesterification of triglycerides in the presence of AA. At high temperature AA, a weak acid, plays the role of an acid catalyst to react with triglycerides

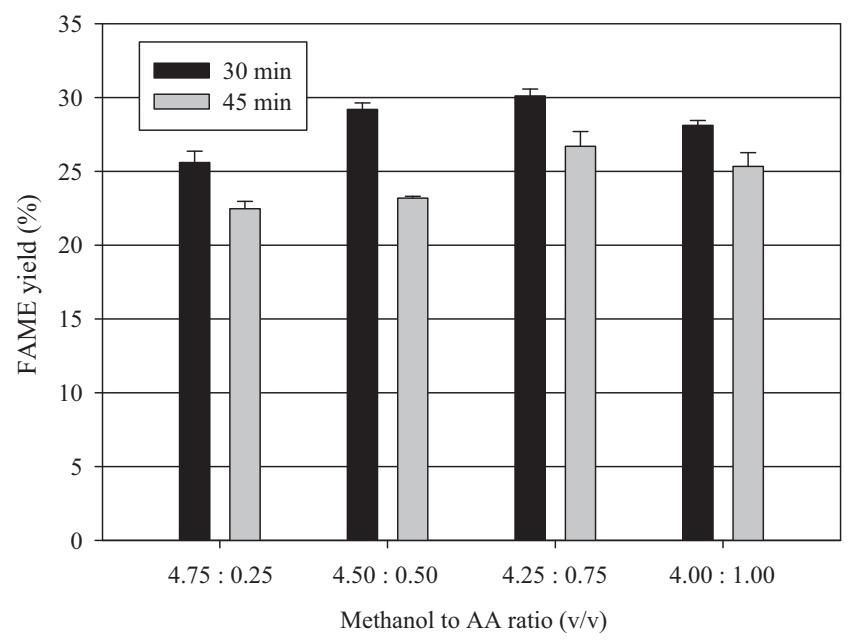

Fig. 5. Effect of AA loading on FAME yield at $250^{\circ} \mathrm{C}$, a solvent (methanol/AA) to dry sludge ration of $5 \mathrm{~mL} \mathrm{~g}^{-1}$ and reaction time of 30 and $40 \mathrm{~min}$. and generate fatty acids, monoacetyl diglyceride, diacetyl monoglyceride and triacetin. These reaction intermediates then react with methanol to produce FAME. Acid (AA) catalyzed transesterification of dry sludge was carried out at $55^{\circ} \mathrm{C}$ with a solvent (methanol:AA $=4.25: 0.75 \mathrm{~mL} \mathrm{~g}^{-1}$ ) to dry sludge ratio of $30 \mathrm{~mL} \mathrm{~g}^{-1}$ resulted in an FAME yield of only $2.61 \%$ in $24 \mathrm{~h}$. Apparently, AA shows high catalytic activity only at high temperature.

Another possible reason for the improvement on FAME yield was the enhancement of lipids extracted from sludge since lipids have better solubility in an acidic environment (Hensarling and Jacks, 1983). AA could also increase the mutual solubility of reactants in the reaction. However, reaction time longer than 30 min (Figs. 5 and 6) and more AA used (Fig. 4, methanol: $\mathrm{AA}=4: 1 \mathrm{~mL} \mathrm{~g}^{-1}$ ) resulted in lower yields owning to possible degradation of products in acidic environment. In this study, a total time of $90 \mathrm{~min}$ (60 $\mathrm{min}$ for heating and $30 \mathrm{~min}$ for reaction) required is significantly shorter than studies on biodiesel production from activated sludge reported in literatures (Table 2).

When pure methanol and a methanol to sludge ratio of $30 \mathrm{~mL} \mathrm{~g}^{-1}$ were used, it was capable of achieving a FAME yield of $28.98 \%$ in 120 min. By using $15 \%$ AA in the AA-methanol mixture and a ratio of AA-methanol mixture to sludge of $5 \mathrm{~mL} \mathrm{~g}^{-1}$, higher yield (30.11\%) can be achieved in much shorter time (30 min).

\subsection{Advantages of using subcritical methanol and $A A$}

Commercial biodiesel production requires the use of acid/base catalyst. Supercritical methanol method has been investigated by many researchers to avoid the use of catalysts. Nevertheless, supercritical methanol has some disadvantages such as high energy consumption and high investment of equipment since the reactions are carried out under high temperature and pressure. Co-solvents such as $\mathrm{CO}_{2}$ and alkane have been added in the supercritical methanol method to reduce the temperature and pressure required for the process, and to reduce the degradation of product (Encinar et al., 2012; Cao et al., 2005). Another possible way is to conduct the reaction under subcritical conditions, with minimum amount of catalysts or without catalyst, at lower temperature and pressure than that required by the supercritical methanol method (Yin et al., 2008).

In terms of reaction time and methanol amount required, the result of in situ transesterification of activated sludge in subcritical methanol and AA obtained in this study is superior to the results of studies that produced biodiesel using conventional acid catalyzed

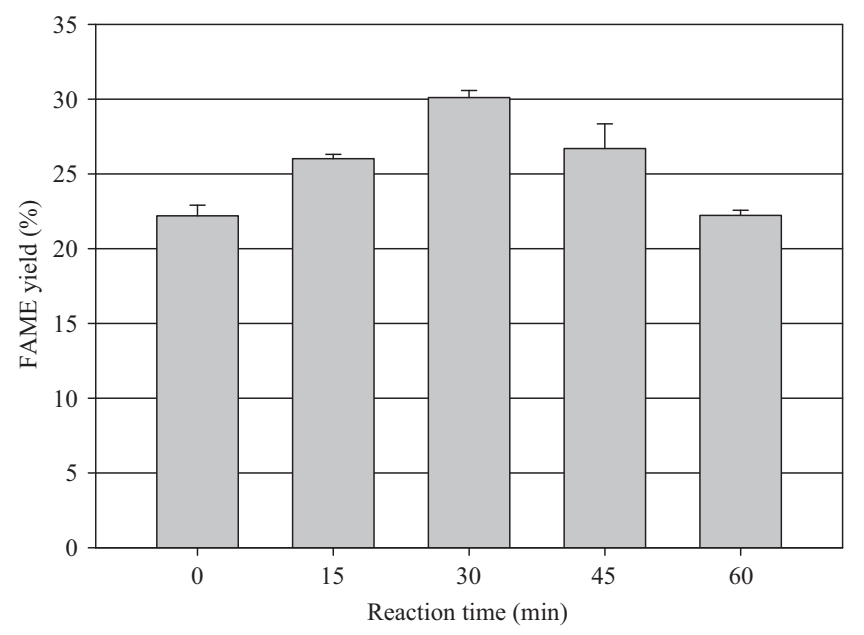

Fig. 6. Effect of reaction time on FAME yield at $250{ }^{\circ} \mathrm{C}$, a solvent (methanol/AA, $15 \%$ acetic acid) to dry sludge ratio of $5 \mathrm{~mL} \mathrm{~g}^{-1}$. 
Table 2

Comparison of results of producing biodiesel from sludge by various methods.

\begin{tabular}{|c|c|c|c|c|c|c|c|c|c|}
\hline Sources of activated sludge & $\begin{array}{l}\text { Lipid } \\
\text { content } \\
(\%)\end{array}$ & $\begin{array}{l}\text { In situ transesterification } \\
\text { method }\end{array}$ & $\begin{array}{l}\text { Ratio } \\
\left(\mathrm{mL} \mathrm{g}^{-1}\right)\end{array}$ & $\begin{array}{l}\text { Temp. } \\
\left({ }^{\circ} \mathrm{C}\right)\end{array}$ & $\begin{array}{l}\text { Time } \\
\text { (h) }\end{array}$ & $\begin{array}{l}\text { Pressure } \\
(\mathrm{MPa})\end{array}$ & $\begin{array}{l}\text { FAME yield } \\
(\mathrm{wt} . \%)^{\mathrm{a}}\end{array}$ & $\begin{array}{l}\text { Conversion } \\
(\%)^{\mathrm{b}}\end{array}$ & References \\
\hline $\begin{array}{l}\text { Municipal wastewater treatment } \\
\text { plant }\end{array}$ & $27.43^{\mathrm{c}}$ & Acid catalyzed $\left(\mathrm{H}_{2} \mathrm{SO}_{4} 1 \% \mathrm{v} / \mathrm{v}\right)$ & 5 & 50 & 24 & - & 6.23 & 22.60 & $\begin{array}{l}\text { Dufreche } \\
\text { et al. } \\
\text { (2007) }\end{array}$ \\
\hline $\begin{array}{l}\text { Municipal wastewater treatment } \\
\text { plant } \\
\text { Primary sludge } \\
\text { Secondary sludge }\end{array}$ & n.r. ${ }^{d}$ & Acid-catalyzed $\left(\mathrm{H}_{2} \mathrm{SO}_{4} 5 \% \mathrm{v} / \mathrm{v}\right)$ & 12 & 75 & 8 & - & $\begin{array}{l}14.50 \\
\text { (primary } \\
\text { sludge) } \\
2.50 \\
\text { (secondary } \\
\text { sludge) }\end{array}$ & $97.89^{\mathrm{h}}$ & $\begin{array}{l}\text { Mondala } \\
\text { et al. } \\
(2009)\end{array}$ \\
\hline $\begin{array}{l}\text { Municipal wastewater treatment } \\
\text { plant }\end{array}$ & n.r. ${ }^{d}$ & Acid-catalyzed $\left(\mathrm{H}_{2} \mathrm{SO}_{4} 4 \% \mathrm{v} / \mathrm{v}\right)$ & 30 & 55 & 24 & - & 4.79 & - & $\begin{array}{l}\text { Revellame } \\
\text { et al. } \\
\text { (2010) }\end{array}$ \\
\hline $\begin{array}{l}\text { Municipal wastewater treatment } \\
\text { plant }^{\mathrm{d}}\end{array}$ & n.r. ${ }^{d}$ & $\begin{array}{l}\text { Acid-catalyzed }\left(\mathrm{H}_{2} \mathrm{SO}_{4} 10 \% \mathrm{v} /\right. \\
\mathrm{v})\end{array}$ & 30 & 75 & 24 & - & 3.93 & - & $\begin{array}{l}\text { Revellame } \\
\text { et al. } \\
(2011)\end{array}$ \\
\hline $\begin{array}{l}\text { Uni-President Enterprises Corp. Ltd., } \\
\quad \text { Chung-Li Bakery Factory }\end{array}$ & 66.64 & $\begin{array}{l}\text { Subcritical water-subcritical } \\
\text { methanol }\end{array}$ & 30 & 175 & 8 & 3.5 & 45.58 & 66.52 & $\begin{array}{l}\text { Huynh } \\
\text { et al. } \\
\text { (2012) }\end{array}$ \\
\hline Wastewater treatment plant & n.r. ${ }^{d}$ & $\begin{array}{l}\text { Acid-catalyzed }\left(\mathrm{H}_{2} \mathrm{SO}_{4} 0.05 \%\right. \\
\mathrm{v} / \mathrm{v}, \mathrm{n} \text {-hexane as co-solvent })\end{array}$ & 10 & 55 & 8 & - & 9.68 & - & $\begin{array}{l}\text { Choi et al. } \\
\text { (2014) }\end{array}$ \\
\hline $\begin{array}{l}\text { Municipal wastewater treatment } \\
\text { plant (greasy, primary and } \\
\text { secondary sludge) }\end{array}$ & 44.40 & $\begin{array}{l}\text { Acid-catalyzed }\left(\mathrm{H}_{2} \mathrm{SO}_{4} 7 \mathrm{wt} . \% \text {, }\right. \\
\text { n-hexane as co-solvent } 10 \% \mathrm{v} / \\
\text { v) }\end{array}$ & 20 & 55 & 7 & - & 61.00 & $>100^{\mathrm{i}}$ & $\begin{array}{l}\text { Gerhard } \\
\text { et al. } \\
\text { (2015) }\end{array}$ \\
\hline Hsin-Tung-Yang LTD Da-Yuan Factory & $45.42^{\mathrm{f}}$ & $\begin{array}{l}\text { Subcritical methanol-AA (AA } \\
15 \%)\end{array}$ & 5 & 250 & $1.5^{\mathrm{g}}$ & 2.5 & 30.11 & 65.97 & This study \\
\hline
\end{tabular}

\footnotetext{
a Yield based on dry sludge.

b Assume that palmitic triglyceride is the major component of lipid and palmitic acid methyl ester is a main component of FAME.

c Maximum oil yield, sludge was extracted three times: $60 \%$ hexane/20\% methanol/20\% acetone.

d n.r.: not reported.

e Wet sludge was used.

${ }^{f}$ Extracted crude oil after SCW treatment for $15 \mathrm{~min}$ at $175^{\circ} \mathrm{C}$ (Tran-Nguyen et al., 2013).

$\mathrm{g}$ Total reaction time including heating time.

h Estimated by on their kinetic model.

i Sludge sample contains greasy, primary-settling and secondary sludge.
}

method and subcritical water-subcritical methanol method. Compared to supercritical methods, this process can reduce the severity of process parameters without sacrificing on biodiesel yield. As shown in Table 2, the $5 \mathrm{~mL}$ methanol/AA per gram dry sludge used in this study is lower than most conventional processes reported in literatures using acid as catalyst which required a methanol to dry sludge ratio of $10-30 \mathrm{~mL} \mathrm{~g}^{-1}$, except for the study of Dufreche et al. (2007) in which a ratio of $5 \mathrm{~mL} \mathrm{~g}^{-1}$ was also used. Production of biodiesel from activated sludge via subcritical methanol and AA seems feasible and superior to the conventional acid/base catalyzed transesterification method.

Dufreche et al. (2007) reported a conversion of $22.60 \%$ which is about one third of the conversion obtained in this study although the amount of methanol used is the same. However, this study can reduce the reaction time to 30 min which is much shorter than the $24 \mathrm{~h}$ required in the study of Dufreche et al. (2007). Compared to the study of Huynh et al. (2012) which required a reaction time of $8 \mathrm{~h}$, this study required $30 \mathrm{~min}$ to achieve the same conversion. Mondala et al. (2009) obtained a conversion of $97.89 \%$ which is significantly higher than that of this study (65.97\%). However, a reaction time of $10 \mathrm{~h}$ and a methanol to dry sludge ratio of $12 \mathrm{~mL} \mathrm{~g}^{-1}$ were required which are much higher than the $1.5 \mathrm{~h}$ reaction time and $5 \mathrm{~mL} \mathrm{~g}^{-1}$ methanol to sludge ratio used in this study. Additionally, the high concentration of sulfuric acid (5\%) used in the study of Mondala et al. (2009) required neutralization as well as separation and washing post-treatment.

Moreover, the use of co-solvent as hexane was eliminated in in situ transesterification subcritical methanol and acetic acid process. Since no mineral acid was used, neutralization and separation of catalysts as well as washing step in the traditional biodiesel production after reaction are not required. Additionally, compared to the acid catalyzed in situ transesterification, this process can drastically reduce the reaction time and methanol loading. The failure to meet the sulfur specification from the generation of sulfurcontaining compounds in the presence of $\mathrm{H}_{2} \mathrm{SO}_{4}$ will no longer be a concern. It can be said that in situ transesterification using subcritical methanol and AA is an environmentally friendly process. The disadvantage of this process is the reaction has to be carried out at considerably higher temperature than the conventional acid/base catalyzed processes.

\section{Conclusions}

This work studied the biodiesel production from activated sludge in subcritical methanol and AA. The reaction was carried out in short time, acid neutralization after reaction was not required and methanol used was significantly reduced. Results show that AA played an important role in the reaction. A FAME yield of $30.11 \%$ was obtained at $250{ }^{\circ} \mathrm{C}$ in $30 \mathrm{~min}$ using a solvent to dried sludge ratio of $5 \mathrm{~mL} \mathrm{~g}^{-1}$. This method requires much shorter reaction time and considerably less methanol amount in producing biodiesel from activated sludge than those reported in literatures.

\section{Acknowledgement}

This work was supported by funding from National Science Council of Taiwan (NSC 102-2221-E-011-079). 


\section{References}

Ahmad, M., Khan, M.A., Zafar, M., Sultana, S., 2012. Practical Handbook on Biodiesel Production and Properties. CRC Press, Taylor \& Francis Group, Florida.

Amit, S., 2012. Biodiesel: Production and Properties. The Royal Society of Chemistry, Cambridge.

Atabani, A.E., Silitonga, A.S., Badruddin, I.A., Mahlia, T.M.I., Masjuki, H.H., Mekhilef, S., 2012. A comprehensive review on biodiesel as an alternative energy resource and its characteristics. Renew. Sustainable Energy Rev. 16, 2070-2093.

Cao, W.L., Han, H.W., Zhang, J.C., 2005. Preparation of biodiesel from soybean oil using supercritical methanol and co-solvent. Fuel 84, 347-351.

Choi, O.K., Song, J.S., Cha, D.K., Lee, J.W., 2014. Biodiesel production from wet municipal sludge: Evaluation of in-situ transesterification using xylene as a cosolvent. Bioresour. Technol. 166, 51-56.

Dufreche, S., Hernandez, R., French, T., Sparks, D., Zappi, M., Alley, E., 2007. Extraction of lipids from municipal wastewater plant microorganisms for production of biodiesel. J. Am. Oil Chem. Soc. 84, 181-187.

Eevera, T., Rajendran, K., Saradha, S., 2009. Biodiesel production process optimization and characterization to assess the suitability of the product for varied environmental conditions. Renew. Energy 34, 762-765.

Encinar, J.M., González, J.F., Sabio, E., Ramiro, M.J., 1999. Preparation and properties of biodiesel from Cynara cardunculus L. oil. Ind. Eng. Chem. Res. 38, 2927-2931.

Encinar, M., Pardal, A., Martínez, G., 2012. Transesterification of rapeseed oil in subcritical methanol conditions. Fuel Process. Technol. 94, 40-46.

Fan, X., Burton, X., 2009. Recent development of biodiesel feedstocks and the applications of glycerol: a review. Open Fuel Energy Sci. J. 2, 100-109.

Gerhard, N.S., Cea, M., Risco, V., Navia, R., 2015. In situ biodiesel production from greasy sewage sludge using acid and enzymatic catalysts. Bioresour. Technol. 179, 63-70.

Hensarling, T.P., Jacks, T.J., 1983. Solvent extraction of lipids from soybeans with acidic hexane. J. Am. Chem. Soc. 60, 783-784.

Huynh, L.H., Tran-Nguyen, P.L., Ho, Q.P., Ju, Y.H., 2012. Catalyst-free fatty acid methyl ester production from wet activated sludge under subcritical water and methanol condition. Bioresour. Technol. 123, 112-116.
Kusdiana, D., Saka, S., 2001. Kinetics of transesterification in rapeseed oil to biodiesel fuel as treated in supercritical methanol. Fuel 80, 693-698.

Kusdiana, D., Saka, S., 2004. Effects of water on biodiesel fuel production by supercritical methanol treatment. Bioresour. Technol. 91, 289-295.

Mata, T.M., Martins, A.A., Caetano, N.S., 2010. Microalgae for biodiesel production and other applications: a review. Renew. Sustainable Energy Rev. 14, 217-232.

Mondala, A., Liang, K., Toghiani, H., Hernandez, R., French, T., 2009. Biodiesel production by in-situ transesterification of municipal primary and secondary sludges. Bioresour. Technol. 100, 1203-1210.

Mythili, R., Venkatachalam, P., Subramanian, P., Uma, D., 2014. Production characterization and efficiency of biodiesel: a review. Int. J. Energy Res. 38 1233-1259.

Noureddini, H., Zhu, D., 1997. Kinetics of transesterification of soybean oil. J. Am. Oil Chem. Soc. 74, 1457-1463.

Olkiewicz, M., Fortuny, A., Stüber, F., Fabregat, A., Font, J., Bengoa, C., 2015. Effects of pre-treatments on the lipid extraction and biodiesel production from municipal WWTP sludge. Fuel 141, 250-257.

Revellame, E., Hernandez, R., French, W., Holmes, W., Alley, E., 2010. Biodiesel from activated sludge through in-situ transesterification. J. Chem. Technol. Biotechnol. 85, 614-620.

Revellame, E., Hernandez, R., French, W., Holmes, W., Alley, E., Callahan II, R., 2011 Production of biodiesel from wet activated sludge. J. Chem. Technol. Biotechnol. 86, 61-68.

Saka, S., Isayama, Y., IIham, Z., Jiayu, X., 2010. New process for catalyst-free biodiese production using subcritical acetic acid and supercritical methanol. Fuel 89 1442-1446.

Tran-Nguyen, P.L., Go, A.W., Huynh, L.H., Ju, Y.H., 2013. A study on the mechanism of subcritical water treatment to maximize extractable cellular lipids. Biomass Bioenergy 59, 532-539.

Yin, J.Z., Xiao, M., Wang, A.Q., Xiu, Z.L., 2008. Synthesis of biodiesel from soybean oil by coupling catalysis with subcritical methanol. Energy Convers. Manage. 49, 3512-3516. 